\title{
A case of external auditory canal osteoma complicated with cholesteatoma, mastoiditis, labyrinthitis and internal auditory canal pachymeningitis
}

\author{
Un caso di osteoma del condotto uditivo esterno complicato da colesteatoma, \\ mastoidite, labirintite e pachimeningite del condotto uditivo interno
}

\author{
I. IACCARINO'1, F. BOZZETTI'2, L.O. PICCIONI ${ }^{3}$, M. FALCIONI ${ }^{1}$ \\ ${ }^{1}$ Otorhinolaryngology and Otoneurosurgery Department, University Hospital of Parma, Italy; ${ }^{2}$ Neuroradiology \\ Department, University Hospital of Parma, Italy; ${ }^{3}$ Otorhinolaryngology Department, San Raffaele Scientific Institute, \\ Milan, Italy
}

\section{SUMMARY}

The association between external auditory canal osteoma and external auditory canal cholesteatoma is rare, with only a few reports in the current literature. Intracranial complications are very rare in the external auditory canal cholesteatoma, especially with direct propagation through the internal auditory canal. A case of 27-year-old male presenting with external auditory canal osteoma with secondary external auditory canal cholesteatoma is described. Progression of the disease created in turn a mastoiditis, labyrinthitis and pachymeningitis confined to the internal auditory canal. The patient was treated by a subtotal petrosectomy, without entering the internal auditory canal. A control MRI after 3 months showed reduction of the internal auditory canal enhancement.

KEY WORDS: Cholesteatoma $\bullet$ Osteoma $\bullet$ External auditory canal $\bullet$ Labyrinthitis $\bullet$ Pachymeningitis

\section{RIASSUNTO}

L'associazione tra osteoma del condotto uditivo esterno e colesteatoma del condotto uditivo esterno è rara, con soli pochi casi descritti in letteratura. Le complicanze intracraniche del colesteatoma del condotto uditivo esterno sono molto rare, specialmente con diretta propagazione attraverso il condotto uditivo interno. Descriviamo il caso di un uomo di 27 anni con colesteatoma del condotto uditivo esterno, secondario ad osteoma del condotto uditivo esterno. La patologia si è complicata con mastoidite, labirintite e pachimeningite confinata al condotto uditivo interno. Il paziente è stato trattato con petrosectomia subtotale, senza aprire il condotto uditivo interno. La RMN di controllo, 3 mesi dopo, mostrava una riduzione dell'enhancement del condotto uditivo interno.

PAROLE CHIAVE: Colesteatoma $\bullet$ Osteoma $\bullet$ Condotto uditivo esterno $\bullet$ Labirintite $\bullet$ Pachimeningite

\section{Introduction}

An osteoma involving the external auditory canal (EAC) has been estimated in $0.05 \%$ of patients requiring ear surgery ${ }^{1}$. The association between EAC osteoma and external auditory canal cholesteatoma (EACC) is rare, with only a few reports in the current literature ${ }^{1}$. EACC is the most common complication of EAC osteoma ${ }^{2}$. The most common complications of EACC, due to extension to the mastoid or middle ear, are facial palsy, ossicles erosion and labyrinthine fistula ${ }^{3}$.

Otogenic brain abscess and meningitis may represent the intracranial complications of standard middle ear cholesteatoma ${ }^{1}$, but they occur exceptionally in EACC, with only one case reported in the literature ${ }^{1}$.

We describe the case of 27-year-old male presenting with EAC osteoma and secondary EACC, complicated with mastoiditis, labyrinthitis and internal auditory canal (IAC) pachymeningitis.

\section{Clinical case}

A 27-year-old male patient with a history of obstruction of the right EAC reported since he was 10 years old and progressive ipsilateral hearing loss, presented to another centre during summer 2015 with right sided otalgia, 

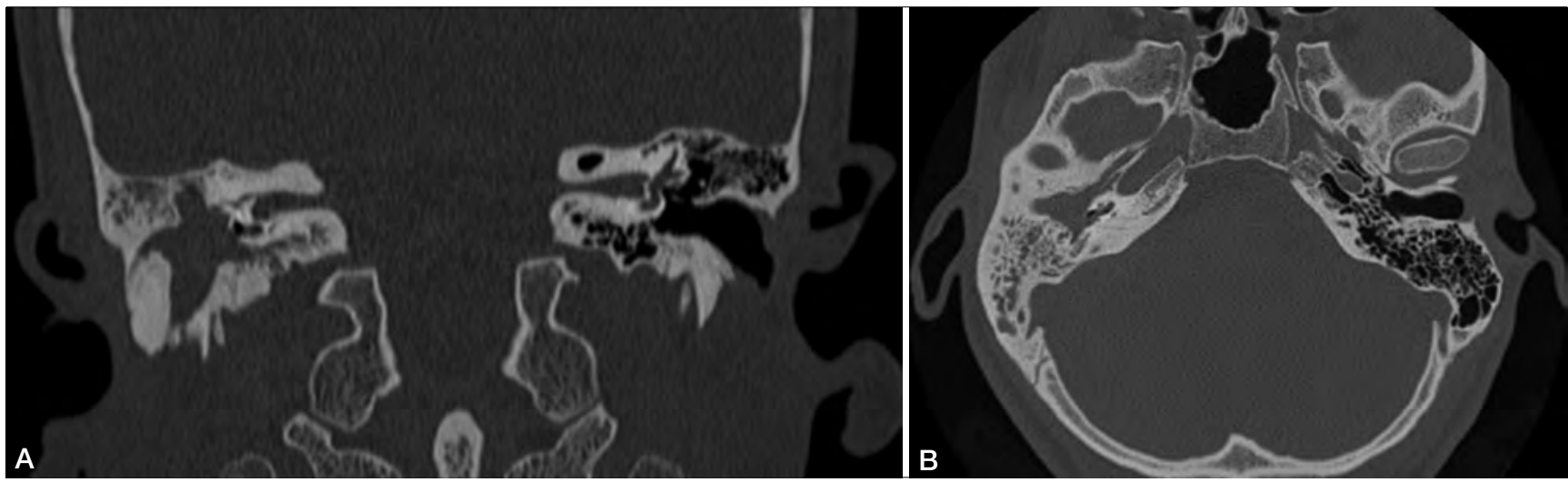

Fig. 1. CT scan with bone window; A) coronal view: a large bony mass obstructs the right external auditory canal. This latter and the middle ear are occupied by material with a soft tissue density. The floor of the external auditory canal is eroded as well as the promontorium, with a cochlear fistula confirmed by the presence of air bubbles into the cochlear lumen. B) axial view: the cochlear fistula is best visualised on axial scans.

post-auricolar pain and swelling. Clinical examination revealed complete obstruction of the right EAC by a solid mass. Tonal threshold audiometry showed right anacusis. He had neither facial paralysis nor neurological symptoms. A clinical diagnosis of acute mastoiditis was made.

CT imaging (Fig. 1A and B) showed a bony mass with a large base and obstructing the right EAC. EAC and middle ear were completely occupied by material with a soft tissue density as well as the mastoid cells. The floor of the EAC was eroded as well as the promontorium, with a cochlear fistula confirmed by the presence of air bubbles into the cochlear lumen. An initial ossification of the lateral semicircular canal was also visible. MRI showed enhancement of the vestibule and lateral semicircular canal extending to the all length of the IAC (Fig. 2). High resolution T2 images did not allow any visualisation of ipsilateral perilymphatic fluid, cerebrospinal fluid into the IAC, as well as the 7th and 8 th nerve bundle.

The patient underwent a mastoidectomy to treat the emergency and then was referred to our centre. For unknown reasons, he came to our attention only after 1 year and 3 further episodes of mastoiditis, which were treated with antibiotics and external puncture. After the 3rd recurrence of mastoiditis in May 2016, he finally presented to the authors' department.

At that time, clinical examination confirmed complete obstruction of the EAC by a solid mass, combined with a retro-auricolar fistula in the area of the evacuation of the last mastoiditis. Facial nerve function was normal. Tonal threshold audiometry showed right anacusis.

A new radiological examination (CT and MRI) was planned.
Bone window CT showed the standard mastoidectomy outcomes. The other findings coincided with the previous examination with the addition of a complete ossification of the inner ear. (Fig. 3A and B).

MRI showed a significant reduction of the enhancement of the internal ear and IAC and the 7th and 8th nerve bundle was now partially visualised (Fig. 4A). Coronal and axial diffusion-weighted imaging (TSE DWI b1000 non-EPI) highlighted a focus with restricted diffusion (high signal) within the mass, a ra-

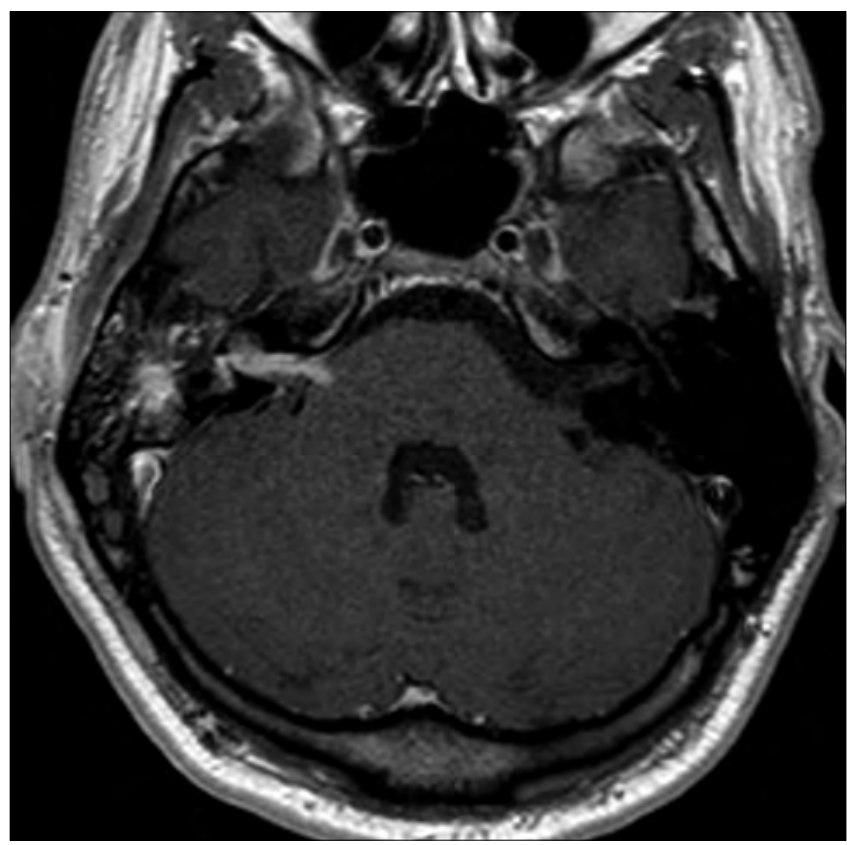

Fig. 2. MRI imaging, $\mathrm{T} 1$ sequence after gadolinium infusion, axial view: gadolinium enhancement of the antrum, vestibule and internal auditory canal. 

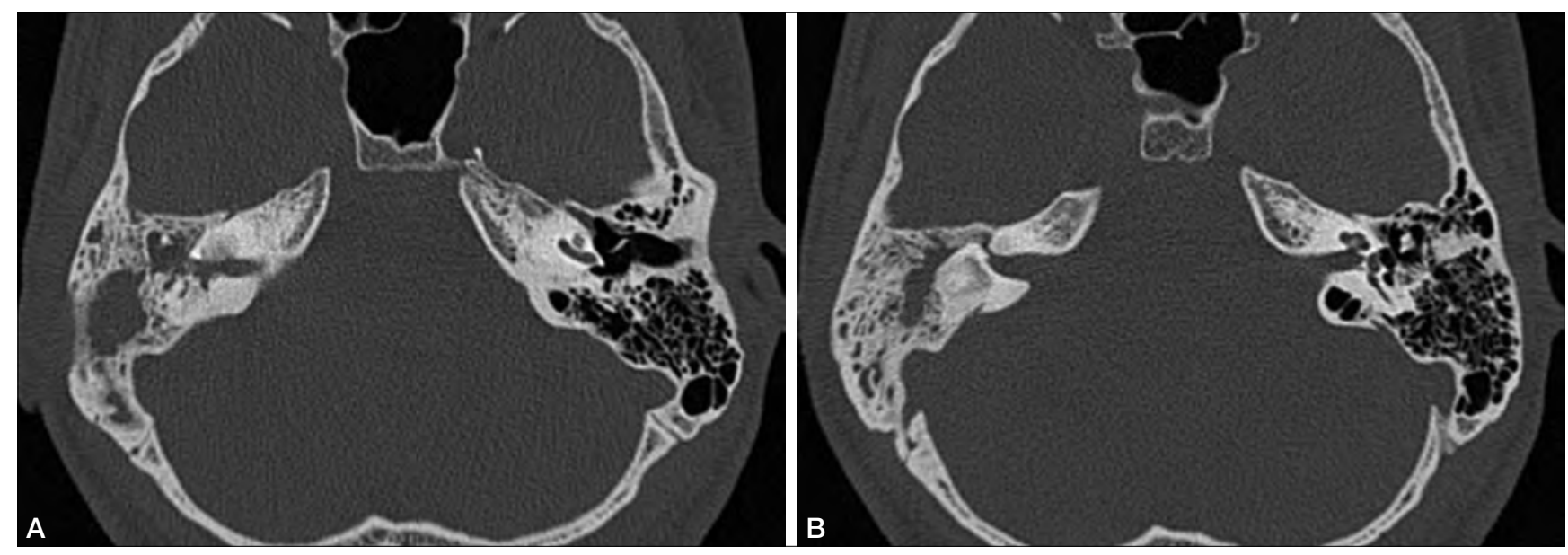

Fig. 3. CT scan with bone window after the first mastoidectomy; A) axial view: regular outcomes of the standard mastoidectomy; complete ossification of the cochlea; B) complete ossification of the vestibule and lateral semicircular canal.

diological finding strongly indicative for presence of cholesteatoma.

Due to the reduction of the IAC enhancement and the normal facial nerve function, it was decided to remove only the infection into the temporal bone by subtotal petrosectomy, leaving the IAC undisturbed. The surgical findings confirmed the presence of cholesteatoma in the EAC and middle ear, with inflammatory tissue in the site of previous mastoidectomy. Fibrous tissue was found to fill the cochlear fistula as well as the vestibule (after removal of the footplate). The resulting surgical cavity was filled with abdominal fat. The patient was placed under intravenous antibiotics and was discharged 3 days after surgery without complications. Three months later, a control MRI showed further reduction of the IAC enhancement (Fig. 4B). A new MRI has been scheduled in 6 months.
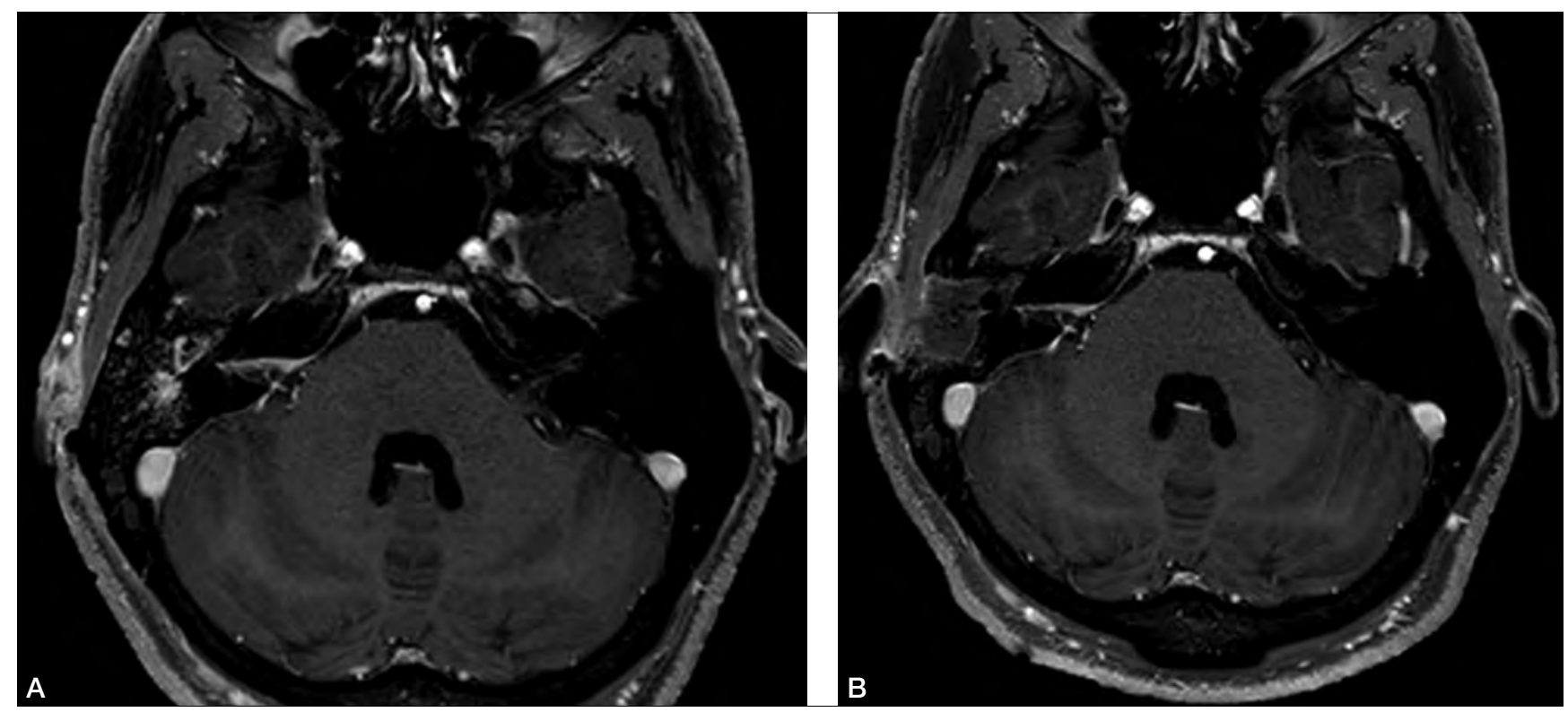

Fig. 4. MRI, T1 sequence after gadolinium infusion, axial view, before surgery: clear reduction of the enhancement of the internal auditory canal; no more enhancement is visible at the level of the inner ear; B) control MRI, T1 sequence after gadolinium infusion, axial view, 3 months after the surgery: external and middle ear are packed with fat tissue; further reduction of the enhancement of the internal auditory canal. 


\section{Discussion}

Osteoma is a benign bony tumour that can be asymptomatic for many years. In the temporal bone, EAC is the most common site of osteoma, usually originating along the tympano-mastoid or tympano-squamous suture lines ${ }^{3-5}$.

The main complication of EAC osteoma, even if rare, is secondary cholesteatoma ${ }^{2}$, which is produced by lateral obstruction of EAC ${ }^{6}$ with medial collection of squamous debris ${ }^{7}$. The bony erosion produced by the EACC may be accelerated by the concomitant chronic infection.

If left untreated, the cholesteatoma may grow medially, involving the middle ear and mastoid, even if in the literature, there are only 3 cases of EACC secondary to osteoma with mastoid invasion ${ }^{1}$.

Progression of the disease may give rise to additional complications such as facial nerve involvement, labyrinthine fistula ${ }^{3}$ and neck abscess ${ }^{8}$.

Cochlear fistula and/or dead ear have not been reported as complications of EACC. Intracranial complications due to EACC secondary to osteoma are exceptional, with only one case in the English literature, namely a cerebellar abscess described in 2007 by Viswanatha ${ }^{1}$ in a 12-year-old female.

Nowadays, at least in the western world, intracranial complications secondary to every type of cholesteatomas are relatively rare. Abscesses are usually located in the temporal lobe and/or cerebellum because the infection progresses through the osseous limits of temporal bone via osteitis and /or bone erosion ${ }^{9}$. Direct infective extension through the IAC is exceptionally rare, with only one case reported in the literature by Martinez et al. in $1999^{10}$. The authors described the case of a 21-yearold man with congenital left sided deafness related to inner ear malformation, and a recent history of headache, left facial weakness and numbness. MRI showed a $1.5 \mathrm{~cm}$ ring enhancing mass involving the pons and the left middle cerebellar peduncle with enhancement also involving the left $7^{\text {th }}$ and $8^{\text {th }}$ nerve bundle, cochlea and vestibule. During surgical exploration through a retrosigmoid approach, biopsy of the $8^{\text {th }}$ cranial nerve confirmed a bacterial neuritis in continuity with a posterior fossa abscess.

The present case showed a sequential occurrence of many rare complications in a case of EAC osteoma. The EAC occlusion produced an EACC (complicated by a mastoiditis) that in turn eroded the cochlea originating a labyrinthitis with direct extension of the inflammation to the IAC for what was diagnosed as a confined pachymeningitis.
The reduction of the IAC enhancement, shown in the $2^{\text {nd }}$ MRI, reinforced the hypothesis of the inflammatory nature of the IAC process. Due to normal facial nerve function and prolonged absence of neurological symptoms, the possibility to limit the surgical intervention to the petrous bone was taken into consideration.

In fact, regression of the IAC enhancement was considered as a sign of an already "cold phase" of the inflammation in the IAC. The final phase of the inflammatory reaction was also confirmed by the progression of the ossification of the inner ear. In this situation, opening of the intradural spaces and connecting them with the main infection in the temporal bone should be discouraged, because it increases the risk of a new infective contamination. In addition, opening the IAC in presence of post-inflammatory scar tissue would put the facial nerve at high risk.

Removal of the main source of infection and periodical radiological control to monitor the progressive regression of the IAC pachymeningitis was considered the best treatment option. The first radiological control performed 3 months after the surgery corroborated the correctness of the surgical option, even if further evaluations will be required before considering the patient completely healed. In case of further increase of the IAC enhancement, exploration of the IAC could be performed through a now sterile route.

\section{Conflict of interest statement}

None declared.

\section{References}

1 Viswanatha B. A case of osteoma with cholesteatoma of the external auditory canal and cerebellar abscess. Int J Pediatr Otolaryngol Extra 2007;2:34-9.

2 Orita Y, Nishizaki K, Fukushima K, et al. Osteoma with cholesteatoma in the external auditory canal. Int $\mathrm{J}$ Pediatr Otorhinolaryngol 1998;43:289-93. https://doi.org/10.1016/s01655876(98)00022-6

3 Lee DH, Jun BC, Park CS, et al. A case of osteoma with cholesteatoma in the external auditory canal. Auris Nasus Larynx 2005;32:2814. https://doi.org/10.1016/j.anl.2005.03.010.

4 Güngör A, Cincik H, Poyrazoglu E, et al. Mastoid osteoma: report of two cases. Otol Neurotol 2004;25:95-7.

5 Samuel W, Aldo C, Serge K et al. Treatment of external auditory canal. Laryngoscope 1998;108:195-9.

6 Cheng Y, Shiao A, Lien CF. Pediatric external canal cholesteatoma with extensive inavsion into the mastoid cavity. Int $\mathrm{J}$ Pediatr Otorhinolaryngol 2005;69:561-6. https://doi.org/10.1016/j. ijporl.2004.10.019.

7 Brookes GB, Grahams MD. Postraumatic cholesteatoma of the external auditory canal. Laryngoscope 1984;94:667-70.

8 Khoyratty F, Sweed A, Douglas S, et al. Osteoma with chole- 
steatoma of the external auditory canal: neck manifestation of this rare association. J Surg Case Rep 2013;2013:1-4. https://doi. org/10.1093/jscr/rjt048.

9 Penido Nde O, Borin A, Iha LC, et al. Intracranial complications of otitis media:15 years experience with 33 patients. Otolaryngol Head Neck Surg 2005;132:37-42. https://doi.org/10.1016/j. otohns.2004.08.007.
10 Martinez SA, Mendelsohn DB, Ginsburg MI, et al. Brain stem abscess with direct extension through the internal auditory canal. Otolaryngol Head Neck Surg 1999;121:474-5. https://doi.org/10.1016/ S0194-5998(99)70240-8.

Received: December 13, 2016 - Accepted: June 6, 2017

How to cite this article: Iaccarino I, Bozzetti F, Piccioni LO, et al. A case of external auditory canal osteoma complicated with cholesteatoma, mastoiditis, labyrinthitis and internal auditory canal pachymeningitis. Acta Otorhinolaryngol Ital 2019;39:358-362. https:// doi.org/10.14639/0392-100X-1547

Address for correspondence: Ilaria Iaccarino, University School of Medicine and Surgery, Department Head and Neck Surgery, Institute of Otorhinolaryngology, "Maggiore" Hospital, via Gramsci, 43126 Parma, Italy. Tel. +39 0521 702364. Fax +39 0521 703788. E-mail: ilariaiaccarino@gmail.com 